\title{
Compulsive Behaviors in the Workplace
}

\author{
Valeriu Deciu
}

UAIC Iasi, Romania

\section{ARTICLE INFO}

Keywords:

Compulsive

Behavior

Repetitiveness

Perfectionism

Obsessiveness

\begin{abstract}
Compulsive behaviors are psychiatric challenges that interfere with the regular life practices of those who exhibit them. This study qualitatively identified compulsive behaviors within three organizations located in no.2 major cities from Romania, aiming to explore their effects on workers' productivity and extended community, including coworkers and employers. To understand the exact behaviors, a literature search was done from Google Scholar to understand examples of compulsive behaviors in the workplace before gathering data from the participants. Using three organizations, from construction materials and adjacent industries, 15 participants were selected and agreed to be interviewed. Further, a survey questionnaire was used to explore the severity and effect of the behaviors on productivity at work. The main results noted workplace compulsive behaviors like repetitive cleanliness, ritualistic behaviors like repetitive ordering or organizing things in a particular manner, persistent repetition of certain words or actions for the perfection of the work assigned, and isolation from other members. The findings from the results entailed an understanding that most compulsive behaviors conflict with established workplace code of conduct. Also, employees confirmed their continued struggle to control the exhibited behaviors. The effects of the behaviors on the employees' productivity and time management were also highlighted. Importantly, most participants confirmed that most employers and coworkers understand their situations and provide social support.
\end{abstract}

\section{Introduction}

Most people attempt to attain their goals by remaining consistent and perfect in every activity they engage in. While the activities are essential since they drive the established goals or vision, most people knowingly indulge in other unrelated repetitive acts that are uncontrollable and do not align with the set goals. In most normal life situations, one finds themselves engaging in activities like checking the door repetitively to confirm if it's locked despite being sure that the door is closed. In other scenarios, one obsessively wonders whether they turned the stove off, hence repetitively checks to ensure it is off even when they are sure that the stove is off. In the workplace, one might engage in a repetitive action like cleaning of a surface even when they know that the surface is already clean, making them unable to attend to other duties on time. Such behaviors are known as compulsive behaviors since they exist as daily rituals characterized by an overwhelming urge to be completed. According to Denys (2014), compulsive behaviour occurs when someone engages in a repetitive action that does not provide reward or relief but repeats it to satisfy particular obsessions. For instance, in a workplace, an employee can repetitively countercheck the assigned work to ensure it is done to the expected standards even when they are sure that the work is done well. As one acts repetitively with the wish to stop the behavior, negative effects are triggered since interpersonal

\footnotetext{
* Corresponding author E-mail address: deciuvaleriu@gmail.com 
conflicts are created, and the mental health is affected as one tries to control or stop them. As noted in the figure below, once one is preoccupied with compulsive behavior, they struggle to stop with little success. Everyday activities associated with compulsion entail shopping, gambling, eating, cleaning, and hoarding. One major characteristic of these behaviors is that despite being done repetitively, one performs them with an understanding that they are not in line with the overall goal being pursued, but they develop no control over them. Hence, in most cases, the behavior is unwanted and dysfunctional as it results in negative outcomes (Allen, King \& Hollander, 2003). As one engages in compulsive behavior, anxiety is created by obsessive thoughts, ideas, and images, making them unable to stop thinking about them. Hence, compulsions are behaviors engaged in to control the developed obsessive thoughts.
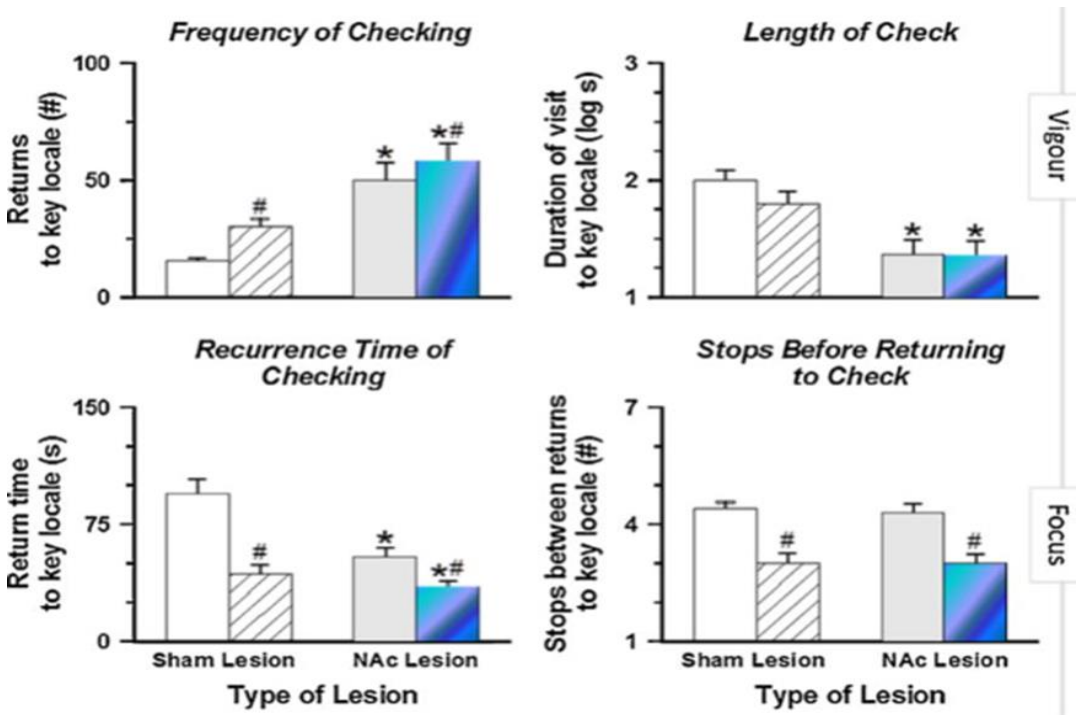

Figure 1. Compulsive checking trait (Szechtman et al., 2017)

\subsection{Elements of compulsive behaviours}

\subsubsection{Phenomenological Elements}

Denys (2014) defined compulsive behavior based on four phenomenological elements: inability to stop performing the act, feeling that one must perform the particular act, lost control, and finally, the unpleasantness of the repetitive acts. Analysis of Denys's findings proves that compulsive behaviors are characterized by a lack of control over the behavior that one indulges in. The feeling that the engaged behavior cannot be stopped or evaded further indicates that it diverges or goes contrary to the voluntary control. As Koob maintains, an addiction gets compulsive when the performance of the behavior is not motivated by an uncontrollable force within oneself (Koob, 2009). Therefore, compulsive behavior in this context implies that one engages in an internal struggle since they are pushed by the feeling of not eliciting the behavior irrespective of the will. As Figee and others hold, one is compelled by an irresistible urge to act since the loss of control functions during such periods (Figee et al., 2013). However, since one behaves out of their control and perspective, then a compulsive behavior has negative consequences. This means that, since compulsive behaviors bring about negative effects, such as not completing the assigned duty at the workplace to attend to a home duty, conflicts with the established goals and responsibilities. Hence, a divergence between volition and behavior from the outsiders' perspective occurs since the employee's behavior brings negative results as the behavior generates no valuable outcome. Additionally, it is critical to understand that the repetitive nature of the behavior signifies its persisting trend and the necessity of its examination due to the effects caused. 


\subsubsection{Observational Elements}

Compulsive behavior is understood from the perspective of four broader observational elements. The first element includes the fact that compulsive behavior is done repetitively, and secondly, the behavior is inappropriate or non-adaptive to the context in which it occurs. The third and fourth observational elements about compulsive behavior are that it results in functional impairment, and finally, it is done in a stereotyped manner. The elements prove that compulsive behaviors are inappropriate within the context they occur (Fineberg et al., 2014). In workplaces, employees are the most affected by the compulsive behavior since it bars them from concentrating or being productive. Similarly, the employee's attention to the assigned duties gets distracted by the behavior elicited, challenging their ability to fulfill the established goals. Nevertheless, the emphasis that the behavior is done in a stereotyped or habitual manner indicates that compulsive behaviors occur in fixed ways that cannot be easily controlled.

\subsubsection{Explanatory Elements}

Fineberg et al. (2010) argue that compulsive behavior occurs due to the perceived consequences attributed to them. A compulsive behavior like frequent washing of a working surface is done by the actor to prevent contamination. Hence, by engaging in such a frequent activity, the actor aims at evading negative consequences associated with a lack of engagement in the act though fails to attend to other activities. In other cases, an external actor's act is perceived as inappropriate since the surface might appear clean. Besides, the other explanatory element is that the actor engages in the behavior to reduce the negative effects of failing to do it like anxiety. In this case, adverse outcomes can entail feelings or a state of discomfort. As earlier explained, compulsive behavior is characterized by an inability to control one's will. Hence, failing to engage in compulsive behavior means conflicting with the will that directs the behavior, thus discomfort of not doing it arises.

\subsection{Common Compulsive Behaviours in the Workplace}

One of the compulsive behaviors noted in the workplace is isolation from other people. Since a compulsive behavior is associated with the feeling of insecurity or fear that failing to do something will elicit a negative consequence, being around people can be interpreted as an activity that can bring undesired effects like being beaten or hurt physically or emotionally. Hence, as an employee with intrusive thoughts gets closer to others, they isolate themselves. In most cases, they opt for phones when they are in meetings or group discussions or walk from meetings without seeking permission. The other example of a compulsive behavior at the workplace is ruminating. Ruminating is an instance where an employee is often disturbed by past scenarios or thoughts in their head. As they contemplate, their concentration on the assigned work is delayed causing them to miss deadlines or underperform in their duty.

Some employees are disturbed by the cleanliness issue in the workplace. To them, continuous cleanliness of the working surface is healthy and helps to avoid diseases. Therefore, they work by cleaning their working surfaces regularly, even when other employees feel that the surface is clean. Hence, at the workplace, employees with regular cleaning behaviors are unable to share a workspace with others because of the contamination fears which trigger panic and anxiety. Employees who fail to act upon such behaviors make the employee quit the job or increases working anxieties and panic to them. Other employees are faced with ritualistic compulsive behaviors that entail constant checkups of particular things at work to ensure they are in order. For instance, an employee working as an auditor does a regular checkup of the balanced statements and financial records to ensure that they are updated and in order. They are carried away by the fear of accountability or transparency, though they forget to attend to other projects. 
Nevertheless, employees affected by the tendency to arrange objects in the workplace at a certain order influence a particular working pattern to other employees, which conflicts with the working environment. Such an employee feels that arranging the objects in a specific way brings about confusion or is not making the workplace presentable, hence resorting to their arrangement plan. Other employees are affected by the tendency to repeat particular actions or words at the workplace that conflicts with the laid code of ethics or professionalism. Attempts by the manager to control the behavior often fail to materialize because of the conditioned tendency of the compulsive behavior and the perceived consequences of not repeating the words or acting in a particular way.

The explained compulsive behaviors affect the performance of the assigned duties, extending to the coworkers, employers, and organizational goals. The continued occurrence of the behaviors often causes a misunderstanding between the employee and the employer as well as the coworkers slowing the progress and productivity of the employee and the working relationship with the affected groups. In instances where the employer and the coworkers show a lack of cooperation with the affected employee, the affected group becomes demotivated or puts things off and struggles in silence since they fear the continued negative opinions or disapproval. Employees from three organizations within Romania were interviewed to assess the compulsive behaviors they exhibit and how their workplaces are affected by them. A further understanding of how the behaviors are exhibited at work and how they affect their daily routines at the workplace was examined.

\section{Methods}

\subsection{Research Design}

An exploratory qualitative design was used to gather data from individuals affected or suffering from a compulsive behavior using qualitative data collection techniques. Semi-structured interviews were carried out to people to assess the effect and extent of the influence of compulsive behaviors.

\subsection{Sample}

Three organizations were used by this study to recruit the participants. The organizations varied in terms of their operations even if all belong to the construction materials industry. The three firms are based in Romania and have a reputable history of performance. To find a sample for this study, the researcher used managers of the mentioned companies who provided names and access to employees with compulsive behaviors. After meeting and discussing with every employee over the concern of the study, 15 employees agreed to the terms, and they were selected. All participants were above 18-years and had a sound mind. Also, a treatment-seeking history related to any compulsive related disorders or compulsive behavior was considered. Nevertheless, the exclusion criteria entailed employees with mental disorders. Hence, the final category of the participants selected entailed $78 \%$ of the selected group were married and males, respectively. The participants' age range was 20-50. Everyone from the group was educated with the highest group having a master's degree qualification.

\subsection{Procedure}

Since the participants were recruited from the company's database as provided by the managers, no attempts were made on recruitment based on socioeconomic status or gender. The employees' recruitment to the study continued until saturation of data was done (Hennink, Kaiser \& Marconi, 2017). Face-to-face semi-structured interviews were applied to participants who had responded to the sent emails confirming their interest in the study. Interviews were 
carried out in the facilities provided by the companies because of convenience. The themes covered entailed the employee's daily experience with the compulsive behavior, coping strategies used to mitigate or contain the issue, relationship with other workers and employers, how the behavior alters personal and organizational productivity or goal-attainment.

Before the start of the interview sessions, the participants completed the Florida ObsessiveCompulsive Inventory questionnaire. The questionnaire helped to measure the severity of the compulsive behavior identified in the employees. Score categories assigned upon completion and assessment of the questionnaires included mild, extreme, moderate, and severe. The severity scale was instrumental to the study since it provided an understanding of the employees' profile to the identified behavior. Employers could use such information for guidance or therapy intervention purposes. To ensure trustworthiness, responses provided by participants were clarified for meaning.

\subsection{Data Analysis}

Interview sessions were recorded using digital tools after the participants agreed to the process. The records were thematically analyzed to understand the sub-themes that characterize compulsive behaviors in the workplace. A qualitative data analysis approach was used to analyze the transcripts. The approach started with familiarizing with the collected data before coding the data extracts to obtain the code list. The third approach allowed researchers to refine the codes before generating the themes. Every theme was then reviewed, as obtained in the third step. The fifth approach entailed refining, allocating, and describing every label to every theme. The final step entailed the presentation of results (Hennink, Kaiser \& Marconi, 2017). Nevertheless, this study employed qualitative research because qualitative studies either generate themes inductively based on the data collected, deductively as obtained from the theoretical framework, or by using data extracted from two methodological methods (Ryan \& Benard, 2003). Based on such understanding, this study used two methods, questionnaires, and interviews.

\section{Results}

As mentioned earlier, 15 employees from three organizations in Romania, were interviewed. The interviewed participants had a mean age of 42.2 years. They all reported compulsive behaviors that disturbed them at the workplace. The majority of the participants interviewed, and those who filled the questionnaire were married and lived with children and or other adults. All of them had graduated from high-schools and universities and were employed part-time and full-time. The salary scale of the participants was EUR 500-EUR 1,500 monthly. $75 \%$ of the employers to the interviewed participants reported a compulsive behavior to the employees. This provided a better framework for understanding the intensity of the behavior and how it affects the wellbeing of the participant, how it manifests in the workplace, and the effect caused at work.

\subsection{Analysis of Themes of Compulsive Behavior in the Workplace}

The major theme, "Compulsive behaviors in the workplace," guided the understanding of the participants' experiences in their respective workplaces. The theme portrays the history of the participant with the compulsive behavior in their normal life routine to their workplaces. Hence, the exploration of sub-themes centered on the specific compulsive behaviors and their effects in the workplace as experienced by the employees. 
Subtheme 1.1. Persistent Repetition of Particular Words and Actions That Conflict Professional Code Participants recounted an experience with a compulsive behavior related to excessive repetition of particular actions and words that are not in line with the established code of conduct at the workplace, causing a misunderstanding with the managers. Two participants considered their behaviors and thoughts as being carried off from the normal work routines and expectations, causing a disturbance to the workplace routine. One participant, I. C., reported that once she completed her studies with commerce major, she got a job at the construction materials company in Romania and had a great time during the first year. She tackled challenging projects that quickly earned her recognition from the employer, causing the organization to recognize her as one of the promising employees. Nevertheless, she has worried because of the inability to control the negative thoughts that invade her mind. At first, no one at the workplace realized her issue, but with time, it manifested as she got it hard completing the assigned projects on time and with perfection. Her major compulsive behavior entailed random negative thoughts that commanded her to reread every work she was working on, over and over until she realized that everything was right. This could take two to three days, even when she knew that the work was perfect and could proceed to the next stage. Her lateness in submitting the assigned orders cause her stress as she has had a lot of work on her desk unattended. She held that "It is like an obsessive thought that I must handle the assigned work again and again until everything is right. It never seems perfect work". Upon reaching her manager, he confirmed that I.C.'s repetitive reading rituals have caused the finance department to lag in several projects. Despite issuing several warnings to her, the behavior had worsened.

Another participant, Daniel (pseudonym) noted:

"The repetitive acts of reading and doing similar things over and over seem ridiculous to many as they are in themselves. To me, they are tormenting cogitations that I struggle with everyday controlling and eradicating."

\section{Sub-Theme 2 Isolation from Others}

In this case, J. D., one of the interviewed participants, remarked her lack of interactive behavior at the workplace with other peers. At the company, she receives customer reviews before forwarding them to the respective management unit for action. Her compulsive behavior at the workplace is isolated from others due to intrusive thoughts that she develops regarding the members of staff. In the interview, she held that "I frequently walk out of meetings even without permission over the fear that something bad might happen to me or a coworker might say or do something bad to me." In most cases where the management is strict, and everyone must be present at the meeting until the discussions are over, J.D. argued that she is constantly on her phone as a way of evading being part of the meeting. In an attempt to understand the rationale or the evolution of the behavior, J.D. held that intrusive thoughts often frequent her mind that being close to people or sharing as a group is bad since people have negative thoughts and intentions about her. The behavior has affected her work since she misses most of the information communicated during meetings and seminars requiring an urgent call for duty.

\section{Sub-Theme 3: Precise Ordering and Arranging Things}

Compulsive behaviors are hard to control even when one knows that they are excessive, and no pleasure is driven from them. In the workplace, engaging in repetitive behaviors makes most of the employees are different since their acts conflict with what others do and believe. In an interview with Maria, she recounted her compulsive behavior that involved acts of perfection in how she wanted her working space and what other employees' work surfaces ought to be. She has been employed for two years, but her ordering and organizing behaviors affect most of 
the coworkers who feel that her behavior contradicts with their organization of working surfaces. While explaining her behavior, Maria noted: "I feel that the working space is not arranged as per the expectation and I arrange it over and over again, mostly after one hour even when nobody has disassembled the arrangement." Maria held that the behavior had caused her so much stress since she concentrates more on arranging and ordering the working space, including that of other coworkers. Poor working relationships have also been created from the behavior as other workers feel that the frequent organization of the office hampers with their appropriate order. Nevertheless, Maria affirmed that she began understanding the negative influence of the behavior once most of the clients stop from contacting her directly, and the coworkers complained of her unending organization habits.

\section{Sub-theme 4: Cleanliness Perfection at the workplace}

Cleaning compulsion is another form of behavior that often distracts employees from delivering expected quality work or adhering to the stipulated standards. I.R. is a 28 -year-old from Bucharest who suffers from contamination fears behaviors at his workplace. He has been employed for three years with daily duties that include managing cash register, ordering stock, and making sales. Despite being given enough time to complete the assigned duties at work, I.R. hardly completes them on time because of the compulsive cleanliness ritual at the workplace. He repetitively cleans the working space, arguing that the place is contaminated and not safe to other employees. The behavior has caused distress at the workplace since I.R. is unable to share the available working space with other employees as demanded by the management. I.R. fears being contaminated with germs and viruses that he constantly claims are in the dirty place despite others perceiving the place to be clean. In confirming the behavior, I.R. argued, "I repetitively wash my hands to the points where they get cracked, bleed and dry for a considerable time. Further, I spend more time scrubbing the desk or even resist shaking hands with people for fear of contracting germs". I.R.'s manager confirmed over the phone that the compulsive behavior contradicts the company's culture that dictates that shaking hands is an ethical standard and allowing other workers and customers to use the working surfaces at any time without interference is healthy. "The management has received several claims about the unwelcoming trait of I.R. over his cleanliness behavior. Most customers have threatened to terminate their partnership with the company because of delayed responses from I.R., who is unable to handle urgent clearances and orders while cleaning surfaces that he thinks are often contaminated". The behavior is, therefore, a hindrance to the better working relationships between employees, coworkers, and their management. Nevertheless, I.R. confirmed that the management has been tolerant of the behavior and has provided him enough time to adapt and change.

\section{Discussion}

This study qualitatively explored compulsive behaviors in the workplace to understand how they manifest and affect the performance and coping aspects of the affected together with employers and coworkers. The study assessed the compulsive behaviors of workers from three organizations in Romania. The findings provide a look at the impact of the behaviors on the attendance to the assigned duties and how their impacts on the performance, productivity, and relationship with coworkers and employers. Further, the findings provide an overview of how the participants struggle to mitigate the effects of the behaviors on their work-life. The study forms part of the qualitative literature that explored the impacts of obsessive-compulsive disorder using exploratory frameworks to develop a better understanding of the signs and effects exhibited by persons suffering from the disorder. Knapton argues in her research paper that most studies on the obsessive-compulsive behaviors are quantitative since they derive their 
findings from pre-defined judgments of the participants instead of unrestricted and extended descriptions (Knapton, 2009). This proves that the analysis of compulsive behaviors, as carried out in this study, needs to be qualitative to provide a contrasting and consistent account of experiences exhibited by the participants from their experience.

In a quest to understand the historical account of the compulsive behavior among employees, the findings proved that the affected perceived the compulsive behavioral symptoms as being normal. They thought that the experiences were normal and exhibited by other employees hence were part of personality traits. As noted in the account of Maria, she started understanding the complexity of the behavior once it began disrupting her normal functioning at work. Notably, the research carried out by (Beşiroğlu \& Ağargün, 2006) proves such effects pointing out that persons affected by compulsive behaviors and disorders lack insights of the excessiveness associated with the symptoms the behavior elicits. Since the behavior occurs repetitively, the affected individuals perceive them as being normal (Abramowitz et al., 2002). They, therefore, exhibit them uncontrollably understanding that nobody is hurt in the process.

In most workplaces, employers emphasize performance and fail to look at the process under which one is supposed to perform. Employers focus on consequences the behavior elicits, including absenteeism, low productivity, and chronic lateness in completing the assigned tasks or the failure to finish the provided projects within the provided time, without looking at the behavior itself. A look at the filled questionnaires proved that most compulsive behaviors are mild and severe, implying that their effects on the individual and their work are high. Most employees interpret such consequences as being caused by a lack of focus and not being keen on time management. In a study on the effect of compulsive behavior within familial contexts, Walseth and others realized that family members who exhibited the behaviors were perceived as being abnormal, causing closer members to carry out close monitoring and surveillance on them (Walseth at al., 2017). In the workplace, the resulting consequence of the behavior is that most companies rather refer their employees to time management counselors when the behavior persists. When such a decision is taken, the compulsion often increases as the worker gets frustrated more since focusing on time management means handling the consequence to the behavior and not the behavior. As Rachman and De Silva point out, the obsessive behaviors are perceived as being normal, causing the actor to increase their frequency (Rachman \& De Silva, 2009). Ultimately, most employers become issue warnings or terminate their employees as observed in most of the interviewed cases where most employers issue warnings and finally terminate the employee.

As pointed out by the participants in the interview sessions, compulsive behaviors in the workplace occur as a response to obsessions that individuals develop over time. The workers in different working environments, as noted in the sessions, engage in compulsive behavior to reduce anxiety associated with obsessive thoughts. In the case of I.R., who is a retailer in one of the organizations in Romania, his compulsive cleanliness behavior is associated with obsessive thoughts of perfection and the fear of contracting diseases from dirty environments. I.R. confirmed that despite trying hard to stop the behavior, he ends up getting caught in the cycle of tension-reduction since obsessions elicit anxiety that other employees at the workplace find hard to cope with. However, the relief is short-lived; the cycle later repeats, causing disturbance again (NIMH, 1994). The occurrence and re-occurrence of the compulsive behavior among employees like I.R. prove that once compulsions start, one finds it hard to stop them because of the anxiety associated with them. The persistent repetition of reading the work done to ensure the work is done to perfection and according to the provided instructions, as exhibited by J.D., proves the point since she is unable to stop even after several warnings from the employer. Such experience coincides with the research carried out by the American Obsessive-Compulsive Foundation, holding that approximately $2 \%$ of the American population 
suffers from compulsive disorders causing irresistible anxiety and panic disorder (Obsessive Compulsive Foundation, 2001). The research coincides with the revelation of most participants like J.D., who affirmed how hard she finds controlling the compulsive behavior due to the anxiety and panic that something wrong will happen. Panic disorder is also exhibited by employees who experience repetitive isolation behavior as they characterize closeness with unknown consequences, making them walk out of meetings without permission.

Such understanding coincides with the research carried out by Paige on the effects of obsessive-compulsive behavior on adolescents and children. To Paige, when the obsessive compulsion is left untreated, obsessive thoughts alter performance, relationships, and attention span (Paige, 2007). As noted from the participants' revelations, concentration on the assigned tasks, as well as performance, is altered by increased compulsive behaviors. Despite the participants exhibiting difficulties in the management of the exhibited behaviors, they argued that the significant others, including their employers and coworkers, have accommodated and tolerated their behaviors. Such finding is consistent with the finding of the study carried out by Palardy and others, proving that social support is significant to patients suffering from obsessive-compulsive behaviors (Palardy et al., 2018). By accommodating employees at work, frustration and anxiety are minimized, making them perceive the workplace as being friendly.

\section{Conclusion}

The qualitative findings obtained in this study explore the lived perceptions and experiences of Romanian employees affected by compulsive behaviors. Effects of compulsive behaviors on the interviewed participants provide in-depth analysis and understanding of the effects and need for mitigation of the behaviors. The findings explored remain consistent with various analyses and results of other qualitative research like the research carried out by the American Compulsive Foundation, analyzing the impacts of compulsive disorders and behaviors. Therefore, the consequences of the compulsive behaviors in the workplace show that the participants find it hard to control them, causing misunderstandings from employers and coworkers. As most of them proved, most employers grow weary of the behaviors elicited due to inability to finish the assigned tasks on time, and the inconveniences caused to other employees. Nevertheless, the provision of social support, understanding, and accommodation to the behaviors and their consequences helps employees to cope up with the demanding work demands.

\section{References}

Abramowitz J.et al. (2002). Religious obsessions and compulsions in a non-clinical sample: the Penn Inventory of Scrupulosity (PIOS). Behav Res Ther. 40:825-38.

Allen A, King A, Hollander E. (2003). Obsessive-compulsive spectrum disorders. Dialogues in Clinical Neuroscience. 5(3):259

Beşiroğlu L \& Ağargün MY. (2006).The correlates of healthcare-seeking behavior in obsessive-compulsive disorder: a multidimensional approach. Turk Psikiyatri Derg. 17:21322.

Denys D. (2014). Compulsivity and free will. CNS Spectrums. 19(1):8-9.

Figee M. et al. (2013). Neurosurgical targets for compulsivity: What can we learn from acquired brain lesions? Neuroscience and Biobehavioral Reviews. 37(3):328-339.

Fineberg N. et al. (2010). Probing compulsive and impulsive behaviors, from animal models to endophenotypes: A narrative review. Neuropsychopharmacology: Official Publication of the American College of Neuropsychopharmacology. 35(3):591-604. 
Fineberg N.et al. (2014). New developments in human Neurocognition: Clinical, genetic, and brain imaging correlates of impulsivity and compulsivity. CNS Spectrums. 19(01):69-89.

Hennink MM, Kaiser BN, Marconi VC. (2017).Code saturation versus meaning saturation. Qual Health Res. 27:591-608.

Knapton O. (2016). Experiences of obsessive-compulsive disorder. Qual Health Res. 26:200923.

Koob G. (2009). Neurobiological substrates for the dark side of compulsivity in addiction. Neuropharmacology. 56:18-31

National Institute of Mental Health. (1994). Obsessive-compulsive disorder. Rockville, MD

Paige, L. Z. (2007). Obsessive-compulsive disorder. Retrieved June 22, 2020, from www.naspweb.org/resources/principals/nassp_obsessive.pdf

Palardy et al. (2018). Social support and symptom severity among patients with obsessivecompulsive disorder or panic disorder with agoraphobia: a systematic review. European Journal of Psychology 14:254-86.

Rachman, S. J., \& de Silva, P. (2009). Obsessive/compulsive disorder (4th Ed.). New York: Oxford University Press.

Ryan GW \& Bernard HR. (2003). Techniques to identify themes. Field Methods. 15:85-109.

Szechtman H, et al. (2017). Obsessive-compulsive disorder: Insights from animal models. Neuroscience and Biobehavioral Reviews. 254-279.

Walseth et al. (2017). Obsessive-compulsive disorder's impact on partner relationships: a qualitative study. J Fam Psychother. 28:205-21. 